purpuric eruptions on the trunk and limbs. On the following day he developed bluish discoloration of several toes of both feet suggesting early gangrene. The skin overlying the area was warm and the peripheral pulses were palpable. The purpuric eruptions became more extensive and he had several bouts of haematemesis. At this stage, the possibility of disseminated intravascular coagulation was considered. No specific diagnostic laboratory test was then available. However, his platelet count was only 25,000 cu.mm. and thrombocytopenia is probably a constant feature in intravascular coagulation.

It was decided to treat the child with continuous intravenous heparin. The decision to anticoagulate the child was not an easy one as we were then faced with the paradoxical situation of gangrene on one hand and spontaneous bleeding on the other. After 48 hours of heparin therapy the child's condition improved remarkably, with rise in platelet count and cessation of spontaneous bleeding. The progress of gangrene was halted. During the course of several days the discoloration of the toes gradually disappeared, apart from small black necrotic areas at the tip of two toes. Heparin therapy was discontinued after seven days. Apart from loss of nail beds of his toes his feet are now perfectly normal.

The diagnosis of intravascular coagulation in this case was made mainly on clinical grounds and it does not fulfil the criteria of this syndrome as suggested by Corrigan and others ${ }^{1}$-namely, the combination of the thrombocytopenia, reduction of coagulation factors II, V, VIII and fibrinogen, and presence of fibrinolytic split products in the serum, but the dramatic response to heparin therapy was gratifying and possibly diagnostic. Disseminated intravascular coagulation or consumption coagulopathy, a relatively new terminology, is well documented in relation to virus diseases. ${ }^{2}-\mathrm{We}$ are, etc.,

\section{A. K. R. Chaudhuri.} Peter MCKenzie.

Belvidere Hospital,
Glasgow E.1.

REFERENCES

1 Corrigan, J. J., jun., Ray, W. L., and May, N., New England fournal of Medicine, 1968, 279, McKay, D. G., and Margaretten. W.. Archide
of Internal Medicine, 1967, 120, 129.

\section{Temporary Cardiac Pacing Using the Subclavian Vein}

SIR,-We were delighted to see the paper by Drs. M. B. Macaulay and J. S. Wright (24 October, p. 207). We hope that these authors' experience with supraclavicular percutaneous introduction of the pacing electrode into the subclavian vein will popularize this little-known technique. Wider appreciation of its enormous advantages over arm-vein routes in terms of electrode stability and comfort for the patient should do much to counter the nihilistic attitude towards the treatment of postinfarction heart block which now prevails in too many centres.

We adopted the subclavian technique some three years ago and can confirm its simplicity, safety, and patient-acceptability. Thanks to clear instructions from $\mathrm{Dr}$. B W Lassers and the enthusiasm of Dr. J. H. N. Bett (now of Melbourne, Australia) the method proved easy to learn. The left subclavian vein is preferred here where temporary pacing is required in patients with chronic heart block so that later use of the right internal jugular vein (for insertion of permanent electrode) is not prejudiced. Use of the left subclavian may also be more convenient for the right-handed operator and the natural curve of the temporary electrode favours correct placement of the tip in the right ventricular apex when introduced from the left side. There are unimportant differences in the equipment used and one potentially important differencethat is, we use only No. 5 F.G. bipolar electrodes, having known the stiffer No. 6 F.G. electrodes to perforate the heart in times gone by.

The Table shows the few complications we have encountered in 60 attempts to establish pacing with the subclavian technique and compares them with the

TABLE.-Comparison of Subclavian and Antecubital routes for Temporary Pacing

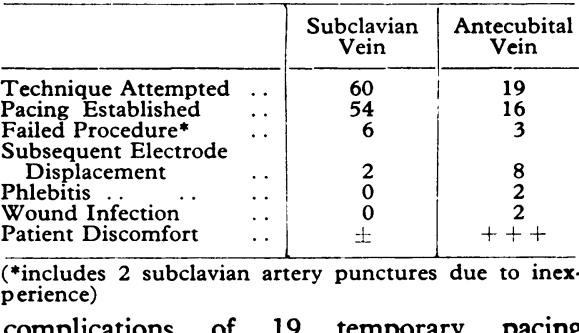

complications of 19 temporary pacing procedures attempted during the same period using antecubital veins. No instances of pneumothorax, brachial plexus injury, or air embolism have been encountered. The latter complication might be anticipated in patients with low central venous pressure unless tilted head down, and in those with obstructive airways disease and uncontrollable coughing; the subclavian technique is unsuitable for use in such cases.

Failure to introduce the electrode into the subclavian vein is now rare (a foam plastic pad, $8 \mathrm{~cm}$. thick, beneath the occiput appears important to success). In a recen case where difficulty was encountered, the patient suffering recurrent asystolic arrest throughout, satisfactory pacing was speedily established via the right internal jugula vein as described by Hoffman and Sokol. ${ }^{3}$ We are, etc.,

\section{David W. Evans.} M. Clarke.

\section{Regional Cardiac Unit, apworth \\ REFERENCES 1 Flanagan, J. P.. Gradisar, I. A., Gross, R. J., \\ Zeft, H. J., Harley, A., Whalen, R. E., and McIntosh, H. D., Circulation, 1967, 36. 456.
offman. R. B., and Sokol, S., American fournal of Roentoenology, Radium Therapy, and
Nuclear Medicine, 1969, 106, 597.}

\section{Malaria in Britain}

SIR,-There are still several deaths every year ${ }^{1}$ in Britain from malaria. A man aged 55 was recently admitted who had been in Nigeria for two weeks, but was not offered or advised about prophylaxis for malaria. Ten days after his return he developed symptoms of a chest infection, and was treated with antibiotics. Five days later he collapsed and was admitted to hospital in coma and profound shock. Cerebral malaria was considered, and the blood film showed heavy infection with Plasmodium falci- parum. Despite intensive treatment his condition slowly deteriorated, and he died a week later.

At necropsy there was very extensive cerebral involvement with numerous haemorrhagic foci having necrotic centres, surrounded by deposits of malaria pigment. In retrospect it is unlikely that he had any chance of survival after the onset of coma.

There is still, despite pressure from many quarters, no one body responsible for providing advice about malaria prophylaxis for travellers. The responsibility must surely lie with both general practitioners and travel agents to provide this much needed advice. This previously fit man was the fifth death due to malaria this year in England-he had no prophylaxis, and the diagnosis was not made until too late. In this age of air travel, it is vitally importan to think of tropical disease in anyone who has recently returned from an endemic area.

Anyone who would like further information concerning malarial endemic areas, and recommended prophylactic schedules, should contact Professor P. C. C. Garnham, at the Malaria Reference Laboratory, Horton Hospital, Epsom, Surrey.-I am, etc.,

\section{T. M. WALKER.}

Salisbury General Infirmary,

Wilts.

1 Department of Health and Social Security. On the State of the Public Health. Annual Report for
Year 1968, p. 36. London, H.M.S.O., 1969.

\section{Skin Disease and the Gut}

SIR,-I have read with interest your leading article (1 August, p. 240) and the subsequent correspondence (29 August p. 521, and 5 September, p. 586) on skin disease and the gut and also the latest contribution of Dr. Janet Marks and Professor S. Shuster on dermatogenic enteropathy (12 September, p. 618). I am writing to draw attention to the similarities between dermatogenic enteropathy and the enteropathy associated with extraintestinal malignant tumors-which can be termed as "neoplastic enteropathy"-and to suggest that folic acid deficiency is mostly responsible for the small bowel dysfunction in both conditions.

Although jejunal mucosal abnormalities have been described in the past in patients with extraintestinal neoplasia ${ }^{12}$ two recent investigations have shown that such changes are indeed very rare. ${ }^{34}$ However, as in dermatogenic enteropathy, malabsorption does exist in the absence of morphological mucosal abnormalities. While the incidence and severity of malabsorption is proportional to the extent of rash in patients with skin disease, they appear to be related to the presence and extent of metastases in patients with carcinoma. ${ }^{4}$

Folic acid deficiency is quite common in patients with extensive skin disease, ${ }^{5}$ as well as in patients with malignant neoplasia, ${ }^{2} 46$ and it is generally believed to be due to an increased demand for the vitamin by the rapid turnover of cells in the skin and the tumor respectively. Folate coenzymes play a key role in cellular division through their action in nucleoprotein synthesis and an impaired synthesis of D.N.A. is a major defect in folate deficiency. ${ }^{7}$ As the cell turnover in the intestinal epithelium is higher than in any other in vivo cell population, interference with normal regeneration of villi, with resulting malabsorption, is only to 